\title{
Sustained Release Strategy Designed for Lixisenatide Delivery to Synchronously Treat Diabetes and Associated Complications
}

Yaping Zhuang, ${ }^{\dagger}$ Xiaowei Yang, ${ }^{\dagger}$ Yamin Li, ${ }^{\dagger}$ Yipei Chen, ${ }^{\dagger}$ Xiaochun Peng,,+ Lin $Y u^{*}{ }^{*}$ Jiandong Ding ${ }^{\dagger}$

†State Key Laboratory of Molecular Engineering of Polymers, Department of Macromolecular Science, Fudan University, Shanghai, 200438, China.

Department of Orthopaedic Surgery, Shanghai Jiaotong University Affiliated Sixth People's Hospital, Shanghai, 200233, China.

*Corresponding Author, E-mail: yu_lin@fudan.edu.cn. 
Table S1. Thermal properties of the copolymers measured by DSC (P1 represents PCGA-PEG-PCGA and P2 represents PLGA-PEG-PLGA)

\begin{tabular}{|c|c|c|c|c|c|c|c|c|c|}
\hline & \multicolumn{4}{|c|}{ PEG block } & \multicolumn{4}{|c|}{ Polyester block } & \multirow[t]{2}{*}{$T_{\mathrm{g}}\left({ }^{\circ} \mathrm{C}\right)$} \\
\hline & $\begin{array}{c}T_{\mathrm{m}} \\
\left({ }^{\circ} \mathrm{C}\right)\end{array}$ & $\begin{array}{l}\Delta H_{\mathrm{m}} \\
(\mathrm{J} / \mathrm{g})\end{array}$ & $\begin{array}{c}T_{\mathrm{c}} \\
\left({ }^{\circ} \mathrm{C}\right)\end{array}$ & $\begin{array}{l}\Delta H_{\mathrm{c}} \\
(\mathrm{J} / \mathrm{g})\end{array}$ & $\begin{array}{c}T_{\mathrm{m}} \\
\left({ }^{\circ} \mathrm{C}\right)\end{array}$ & $\begin{array}{c}\Delta H_{\mathrm{m}} \\
(\mathrm{J} / \mathrm{g})\end{array}$ & $\begin{array}{c}T_{\mathrm{c}} \\
\left({ }^{\circ} \mathrm{C}\right)\end{array}$ & $\begin{array}{l}\Delta H_{\mathrm{c}} \\
(\mathrm{J} / \mathrm{g})\end{array}$ & \\
\hline $\mathbf{P 1}$ & 15 & 4 & -13 & 10 & 35,41 & 40 & 12 & 46 & -59 \\
\hline P2 & - & - & - & - & - & - & - & - & -8 \\
\hline
\end{tabular}
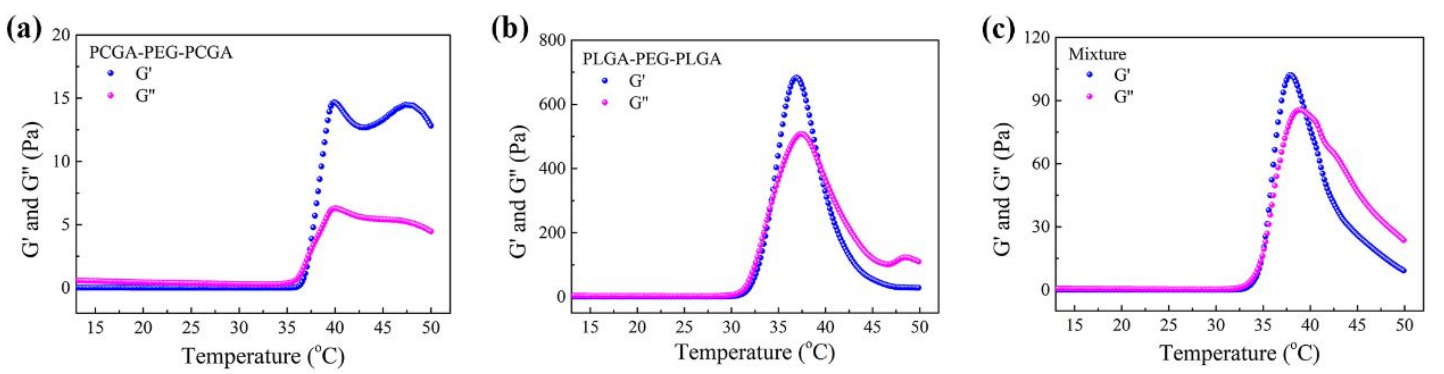

Figure S1. The storage modulus $(G)$ and loss modulus $\left(G^{\prime \prime}\right)$ of (a) PCGA-PEGPCGA, (b) PLGA-PEG-PLGA and (c) the mixture in PBS (pH 7.4) as a function of temperature. Heating rates: $0.5^{\circ} \mathrm{C} / \mathrm{min}$, oscillatory frequency: $10 \mathrm{rad} / \mathrm{s}$. The polymer concentration was $25 \mathrm{wt} \%$. 


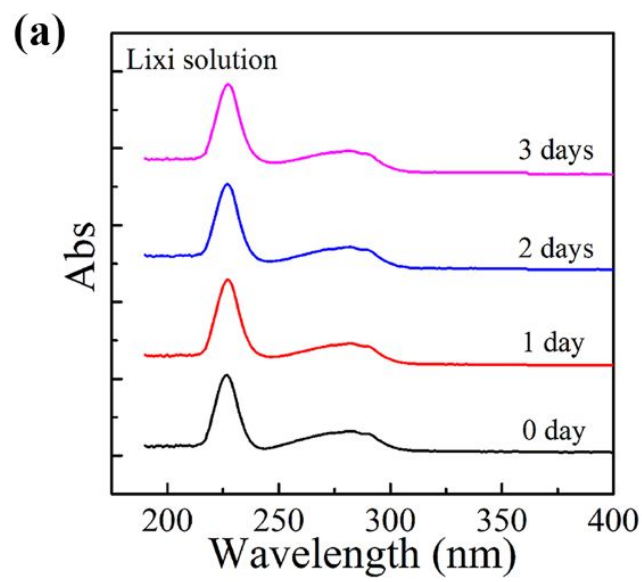

(b)

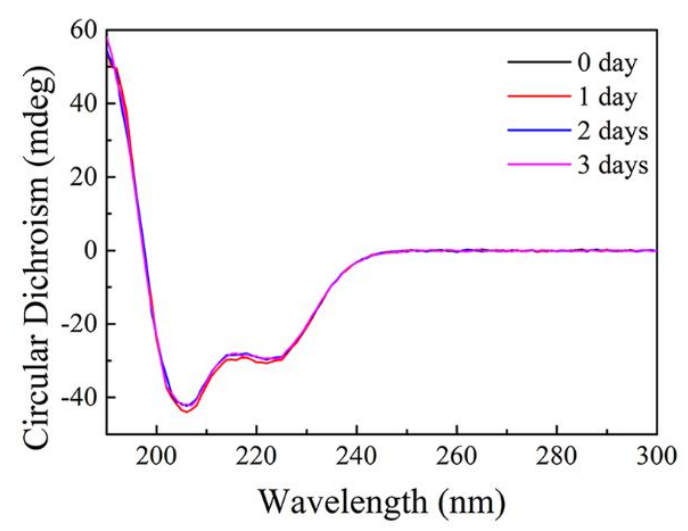

Figure S2. UV-vis (a) and CD (b) spectra of Lixi in PBS at $37^{\circ} \mathrm{C}$ over storage time

Table S2. Assessment of in vitro release of Lixi via the Higuchi and first-order models 


\begin{tabular}{|c|c|c|c|c|c|}
\hline & $\begin{array}{c}\text { concentrati } \\
\text { on }\end{array}$ & $k$ & $R^{2}$ & $k$ & $R^{2}$ \\
\hline PCGA-PEG- & $4 \mathrm{mg} / \mathrm{mL}$ & 0.556 & 0.961 & 0.268 & 0.990 \\
\hline \multicolumn{6}{|l|}{ PCGA } \\
\hline PLGA-PEG- & $4 \mathrm{mg} / \mathrm{mL}$ & 0.353 & 0.911 & 0.451 & 0.998 \\
\hline \multicolumn{6}{|l|}{ PLGA } \\
\hline \multirow[t]{3}{*}{ Mixture } & $1 \mathrm{mg} / \mathrm{mL}$ & 0.398 & 0.979 & 0.201 & 0.997 \\
\hline & $2 \mathrm{mg} / \mathrm{mL}$ & 0.424 & 0.994 & 0.201 & 0.979 \\
\hline & $4 \mathrm{mg} / \mathrm{mL}$ & 0.511 & 0.988 & 0.232 & 0.998 \\
\hline
\end{tabular}

Higuchi model: $Q_{\mathrm{t}}=k t^{1 / 2}, Q_{\mathrm{t}}$ is the cumulative release amount at time $t, t$ is release time, $k$ is the Higuchi constant.

First-order model: $\ln \left(Q_{\mathrm{t}} / Q_{0}\right)=-k t, Q_{\mathrm{t}}$ means the cumulative release amount at time $t$, and $Q_{0}$ is the initial amount of drug in the release medium, $t$ is release time, $k$ is the first order constant. 


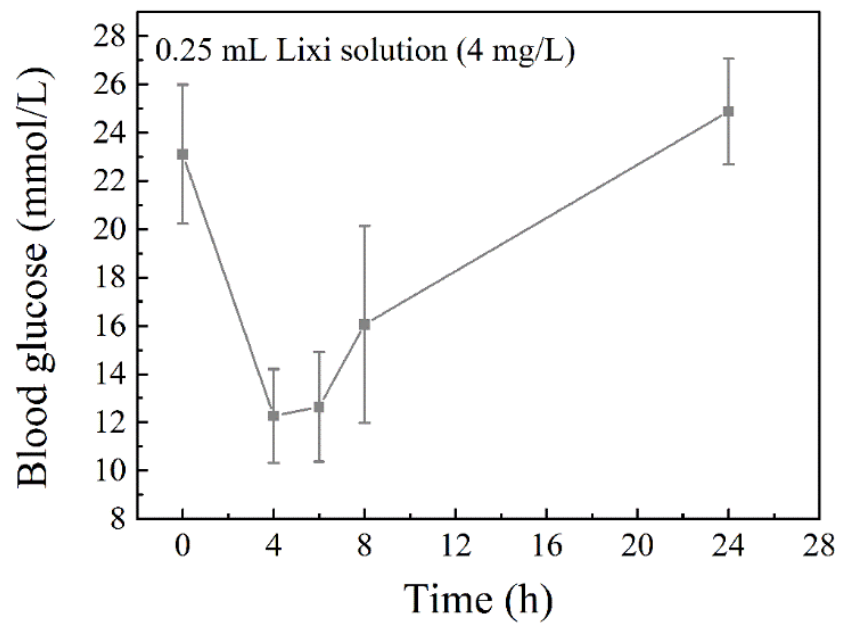

Figure S3. Changes in the blood glucose level as a function of time after a subcutaneous injection of free Lixi. The results are presented as the mean \pm standard deviation (SD) $(n=8)$.

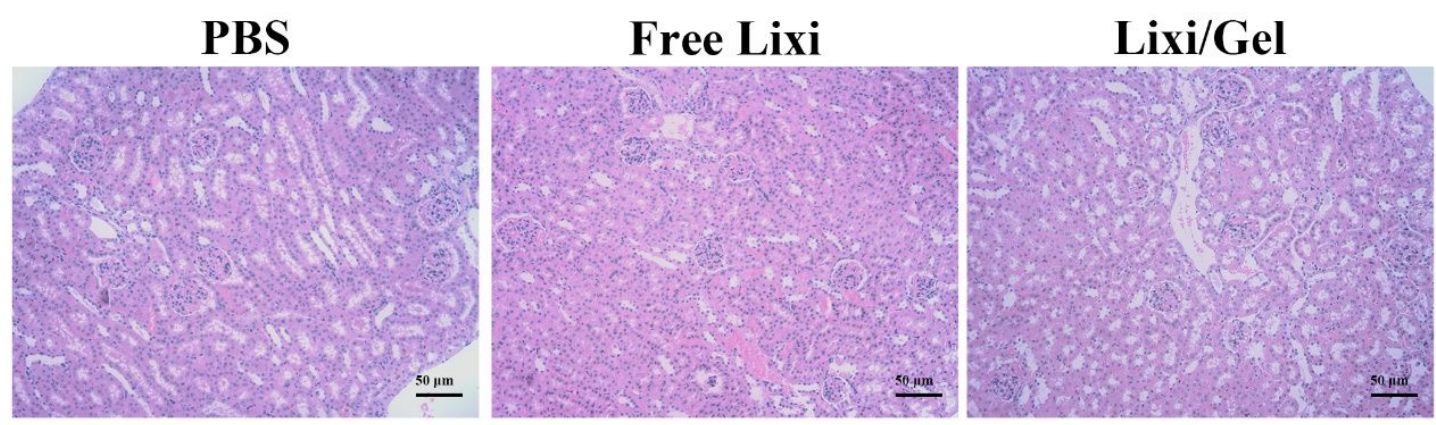

Figure S4. Representative HE-stained histological slices of kidney tissues isolated from the $\mathrm{db} / \mathrm{db}$ mice upon receiving various treatments for a month. 
(a) $\mathrm{NH}_{2}$-HGEGTETSDLSRQMEEEAVRLE-

- IEWLKNGGPSSGAPPPS-CONH

(b) $\mathrm{NH}_{2}$-HGEGTETSDLSRQMEEEAVRLF-

- IEWLRNGGPSSGAPPSKRKRKK-- $\mathrm{CONH}_{2}$

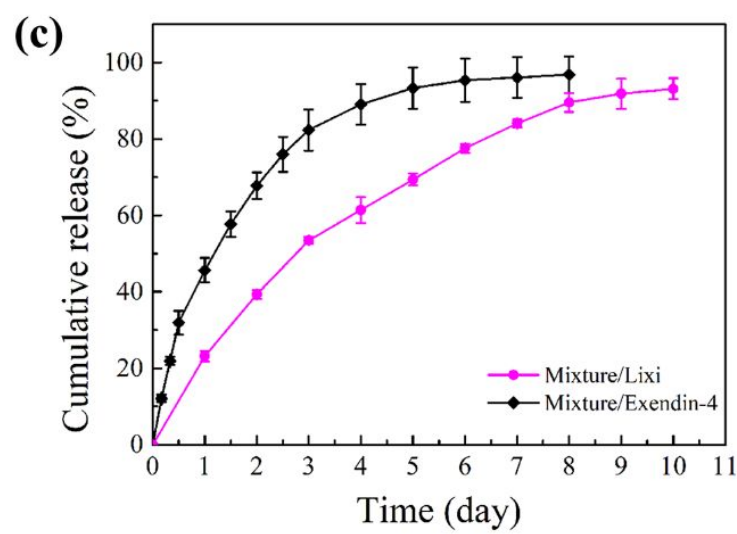

Figure S5. (a) The amino acid sequence of Exendin-4. (b) The amino acid sequence of Lixi. (c) In vitro cumulative release profiles of Lixi and Exendin-4 from the mixture hydrogel. The polymer concentration was $25 \mathrm{wt} \%$ and the concentration of Lixi was $4 \mathrm{mg} / \mathrm{mL}$. The results are presented as the mean \pm standard deviation (SD) $(n=3)$. 